\title{
475183 - INTRAOPERATIVE LIDOCAINE INFUSION SPARES POSTOPERATIVE FENTANYL IN PATIENTS UNDERGOING AMBULATORY LAPAROSCOPIC CHOLECYSTECTOMY
}

\author{
S. Lauwick, MD ${ }^{1}$, G. Michelagnoli, $\mathrm{MD}^{1}$, Do Kim, MD ${ }^{2}$, G. Mistraletti, $\mathrm{MD}^{1}$, Liane \\ Feldman, $\mathrm{MD}^{2}$, Gerald Fried, $\mathrm{MD}^{2}$, Franco Carli, $\mathbf{M D}^{1}$ \\ 1. Anesthesia, McGill, Montreal, QC, Canada \\ 2. Surgery, McGill, Montreal, QC, Canada
}

Introduction: We have recently shown that intraoperative administration of nonanesthetic adjuvants accelerates the recovery process.(1) Intravenous lidocaine has been shown to have significant an opioid sparing effect during the immediate recovery period and shortened hospital stay following major abdominal surgery. The purpose of this study was to determine whether lidocaine infused during the intraoperative period spares the postoperative use of fentanyl in patients undergoing laparoscopic cholecystectomy. Methods: Local REB approval was obtained for this study. Fifty patients were enrolled in this prospective, randomized and observer-blinded study. General anesthesia was standardized with propofol, rocuronium, and desflurane titrated to maintain a BIS between 30 and 60 . The control group $(n=25)$ received fentanyl $3 \mathrm{mcg} / \mathrm{kg}$ at induction while the lidocaine group $(\mathrm{n}=25)$ received a continuous infusion of lidocaine $2 \mathrm{mg} / \mathrm{kg} / \mathrm{h}$ and fentanyl $1.5 \mathrm{mcg} / \mathrm{kg}$ also at induction. Adjuvant medications included, acetaminophen, ketorolac, local anesthetics in the skin incision, dexamethasone and droperidol. Postoperative orders included fentanyl if pain visual analogue score (VAS) was $>4$ and odansetron for persistent postoperative nausea and vomiting (PONV).

Results: The amount of fentanyl required in the postanesthesia care unit was significantly less in the lidocaine group, $90 \pm 52 \mathrm{mcg}$ compared with the control group, $158 \pm 98 \mathrm{mcg}$ $(\mathrm{p}<0.01)$. Eight patients in the control group required odansetron, while there were only 3 in the lidocaine group. The length of stay in hospital was similar in both groups.

Discussion: Intraoperative infusion of lidocaine contributes to a significant decrease in postoperative administration of fentanyl.

References: 1. Collard V, Taqi A, Mistraletti G, Asenjo JF, Feldman L, Fried G, Carli F. Intraoperative esmolol infusion in absence of opioids spares postoperative fentanyl in patients undergoing ambulatory laparoscopic cholecystectomy. Anesthesia and Analgesia, 2007; 105: 1255-62 